\title{
Describing and analyzing landscape patterns: where are we now, and where are we going?
}

\author{
Jennifer K. Costanza $(\mathbb{D} \cdot$ Kurt Riitters $(\mathbb{D} \cdot$ Peter Vogt $\mathbb{C} \cdot$ James Wickham $(\mathbb{D}$
}

Received: 18 January 2019/Accepted: 14 August 2019/Published online: 26 August 2019

(C) Springer Nature B.V. 2019

\section{Introduction}

The description and analysis of landscape patterns became a central research issue in landscape ecology with the emergence of the pattern-process hypothesis (Turner and Gardner 1991). The earliest references to landscape pattern metrics or indices in the peerreviewed literature were in 1987 and 1988 (Fig. 1a). Gardner et al. (1987) compared the number, size, and perimeters of patches across real and simulated landscapes and established the neutral model concept for comparing landscape patterns. Krummel et al. (1987) demonstrated the first multi-scale index-a fractal dimension describing perimeter-area scaling-

J. K. Costanza ( $\bowtie)$

Department of Forestry and Environmental Resources, North Carolina State University, 3041 Cornwallis Rd., Research Triangle Park, NC 27709, USA

e-mail: jennifer_costanza@ncsu.edu

K. Riitters

US Department of Agriculture Forest Service, Southern Research Station, Research Triangle Park, NC 27709, USA

P. Vogt

European Commission, Joint Research Centre (JRC), Via E. Fermi 2749, 21027 Ispra, VA, Italy

J. Wickham

National Exposure Research Laboratory, US

Environmental Protection Agency, Office of Research and

Development, Research Triangle Park, NC 27711, USA while Milne (1988) demonstrated an entire class of multi-scale indices based on fractal geometry. O'Neill et al. (1988) introduced the dominance and contagion indices, the latter of which extended the Shannon species diversity index (e.g. Pielou 1975) to describe the diversity of spatial adjacencies on a map. Those and other early methods capitalized on concepts or metrics developed in diverse fields such as information theory, percolation theory, classical ecology, and fractal geometry.

As more aspects of landscape patterns were recognized, the metrics to quantify those aspects proliferated, so that 10 years later, Gustafson (1998) stated that hundreds of measures of landscape pattern had been proposed. Several reviews have examined the burgeoning array of metrics used in landscape ecology, often with a critical eye (Gustafson 1998; Li and Wu 2004; Kupfer 2012; Lausch et al. 2015; Frazier and Kedron 2017). Critics have taken issue with the long list of metrics that have been applied without knowledge of their ecological meaning or their interpretation with respect to pattern per se. These issues have also limited our ability to integrate results from different studies in two ways. First, the concern about the ecological meaning of a metric is usually addressed by increasing the specificity of the metric according to the objectives and scale of a particular study (Gustafson 2019, this issue). Integration with other studies is then complicated by Levins' (1966) classical tradeoff between the precision (specificity) 
and generality of the metric. Second, and a more important concern from a pattern perspective, is that unless the metric can also be interpreted with respect to pattern per se, the effects of pattern cannot be compared to other studies that use different metrics (Bogaert 2003). Successful integration does not require every study to use the same metric, but it does require knowing what the metric measures and how that underlying aspect of pattern is ecologically relevant.

We suggest the array of landscape metrics has coevolved with improvements to landscape data and computing capacity. Most early methods and metrics for quantifying landscape pattern relied on the conceptual "patch mosaic" landscape model (Forman and Godron 1981; Urban et al. 1987; but see McIntyre and Barrett 1992; and McIntyre and Hobbs 1999 for some notable early exceptions to the patch mosaic concept). The patch mosaic model emerged when most landscape maps were polygon (patch) formatthe earliest landscape ecology studies that examined pattern metrics were based on land use polygon maps converted to categorical raster format for analysis (Gardner et al. 1987; Krummel et al. 1987; O’Neill et al. 1988). The typical map analysis software was raster-based (e.g. GRASS [https://grass.osgeo.org/ home/history), and the earliest implementations of landscape pattern metrics relied heavily on the patch mosaic model and metrics derived from categorical maps (Baker and Cai 1992; McGarigal and Marks 1995). Over time, supported by advances in remote sensing, GIS, and computation, it became more feasible to analyze large data sets representing more aspects of landscape pattern, and other conceptual approaches such as surface metrics from microscopy and molecular physics, connectivity metrics from circuit theory, and pattern recognition from mathematical morphology have emerged recently as promising frameworks for measuring landscape patterns from those maps (Vogt et al. 2007, 2009; McRae 2008; McGarigal et al. 2009; Cushman and Huettmann 2010; Kedron et al. 2018).

Despite the challenges and critiques of landscape pattern measurement, the use of landscape pattern metrics has continued to increase over time (Fig. 1a, see also Uuemaa et al. 2013). And, not only has the development of landscape metrics been informed by other disciplines, but the development and usage of those metrics also has grown to inform a wide range of research in ecology, geography, and beyond (Fig. 1b). For example, in the urban studies literature, patch metrics have been used to classify cities into different morphologies and to investigate the relationship between spatial patterns of green space and urban heat island effects (Schneider and Woodcock 2008; Li et al. 2013; Kong et al. 2014). The relatively new domain of macrosystems ecology attempts to link patterns and processes from broad scales to fine scales, and thus the ability to measure landscape pattern consistently across scales is critical (Fei et al. 2016; Potter et al. 2016). And, the recent emphasis on "conserving nature's stage" in conservation planning requires pattern descriptions of the geodiversity-the variety of topographic, soil, and other abiotic conditions-in a landscape (Beier and Brost 2010; Hjort et al. 2015; Lawler et al. 2015; Zarnetske et al. 2019).

These domains of interest in ecology and conservation biology exemplify the universal reliance in ecology on the measurement of pattern, heterogeneity, and diversity of conditions across landscapes. The growing popularity of "big data" in ecology from remotely-sensed imagery as well as in situ measurements, crowdsourced data, and historical archives (Elith et al. 2006; Hampton et al. 2013; Pettorelli et al. 2014; Franklin et al. 2017; Morrison et al. 2017) points to a future in which previously intractable amounts of information may be leveraged to measure and understand spatial pattern. Landscape ecologists are wellequipped to think critically about the methods and techniques that are used and will be developed for pattern measurement to address these challenges. An examination of landscape pattern measurement, its usage, and best practices, can thus provide valuable insights and leadership to inform that future.

\section{Goals of the special issue}

In this special issue, with the history and future of landscape pattern metrics in mind, we feature a set of perspectives about the measurement of landscape pattern, research articles on emerging pattern metrics and their applications, and a look to new developments in pattern measurement for landscape ecology. We aim to bring attention to integrated pattern-oriented approaches to measuring landscape patterns. In that vein, we have two distinct but related goals-first, to achieve a vibrant discussion of the essential elements 


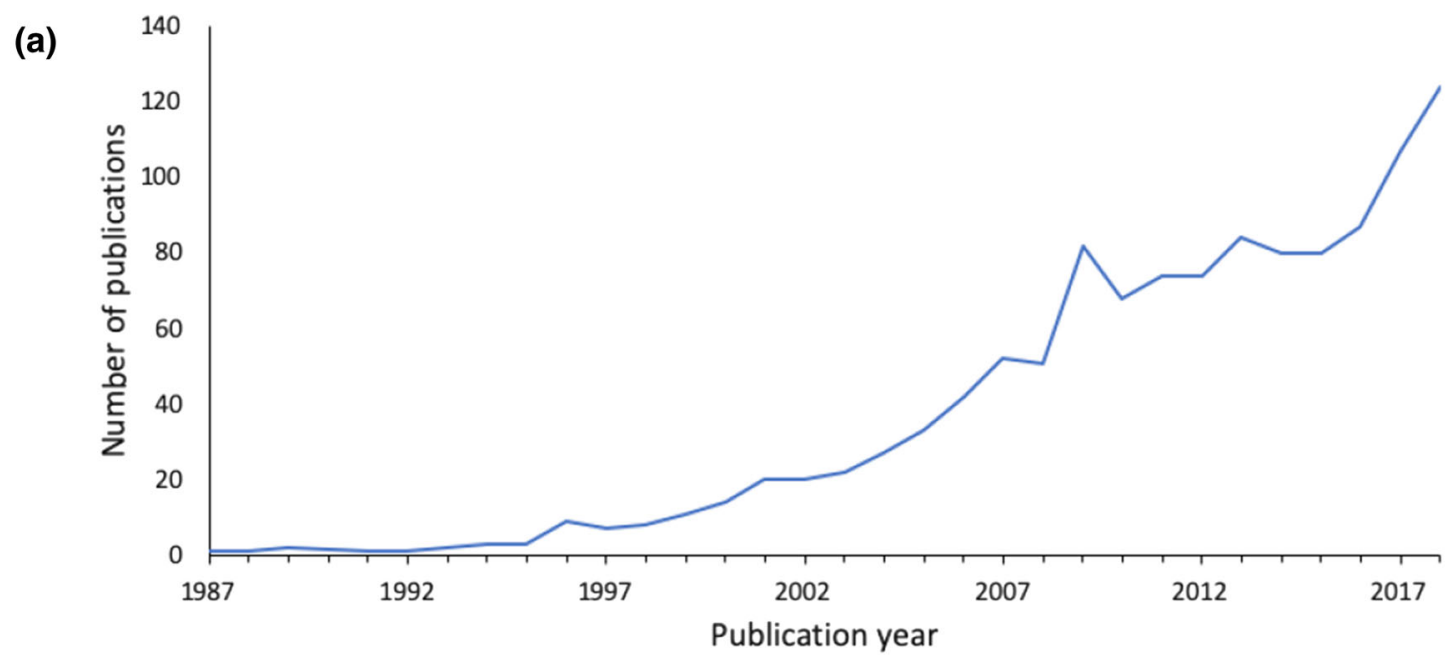

(b)
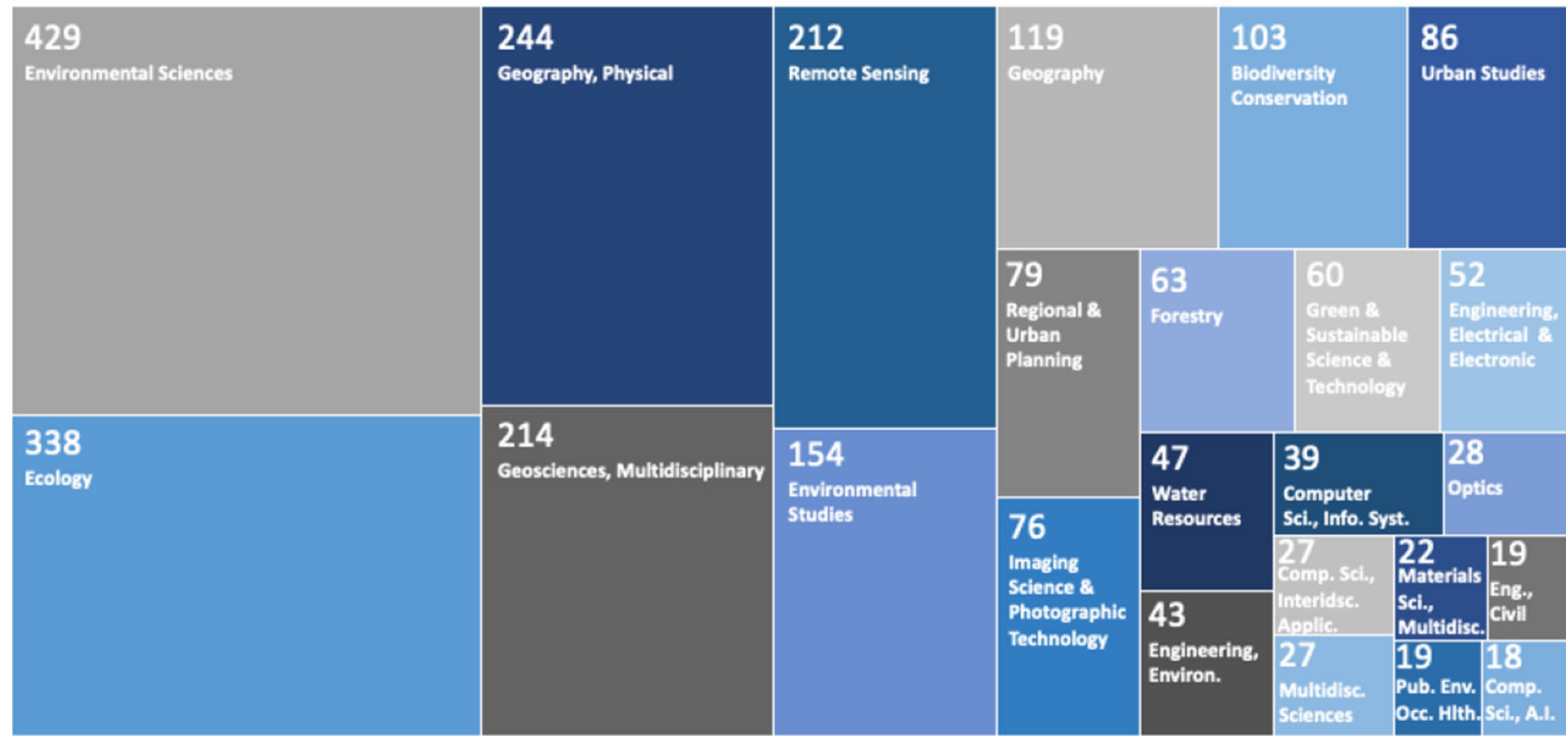

Fig. 1 Number of publications on landscape metrics: a over time, annually; and b by Web of Science subject category. Web of Science search terms used: "TS = ("landscape pattern" AND metric) OR TS = ("landscape pattern" AND index)". Search included all document types during the period 1900 to present,

and descriptors of pattern per se, and second, to provide a venue for "pattern-oriented" ecologists to present new concepts, methods, and applications for measuring and interpreting patterns. Fischer and Lindenmayer (2007) defined a pattern-oriented approach to habitat fragmentation research as one that focuses on correlations between human-perceived landscape patterns and species occurrence. In a transdisciplinary context that is not limited to species'

and 1987 was the 1 st year in which publications were found. The 25 subject categories in Web of Science with the most publications meeting the search criteria over the period are shown in (b). Publications can be classified into more than one subject category

responses to human-perceived patterns, a patternoriented approach also considers other pattern-process outcomes (e.g. water quality, fire regimes), land use planning (e.g. landscape context, sense of place), resource management (e.g. conservation, restoration), assessment science (e.g. ecosystem services, environmental security), along with public perceptions (headline indicators) and integration across these perspectives. The contributions in this issue therefore 
examine a broad range of topics related to measuring pattern that will provide essential information for a wide range of disciplines.

\section{Perspectives on the current state of the field}

To help us reach our goal of a discussion of landscape pattern metrics, this special issue features several perspectives on the current state of the field. Gustafson (2019, this issue) reflects on the fate of some of the approaches that were popular at the time of his nowclassic review (Gustafson 1998) of the state of the art of pattern metrics. Some approaches, such as the graph theoretic methods that were being developed at the time of that paper (Keitt et al. 1997; Urban and Keitt 2001), are still in wide use today (for example, Saura and Torné 2009), while other approaches such as lacunarity analysis (Plotnick et al. 1993) and fractal geometry (Milne 1992) are rarely used. Frazier (2019, this issue) examines how perspectives from other disciplines can contribute to emerging trajectories and move the field of landscape pattern analysis forward. For example, ideas from the field of regional studies could help broaden the concept of landscape connectivity to include similarity in land management initiatives operating on different sites. Riitters (2019, this issue) suggests that achieving the vision of landscape ecology as a transdisciplinary science (Wu 2013) would be facilitated by revisiting the fundamentals of what to measure and how, if the goal is to characterize landscape patterns per se. Vogt (2019, this issue) points out that pattern analysis - attributing meaning to information-is a fundamental aspect of science. He leverages his experiences developing software for morphological spatial pattern analysis (MSPA) (Soille and Vogt 2009) to note that abstraction and provision are fundamental to pattern analysis as well as software development.

\section{New metrics and models}

Several papers in this special issue present new concepts and methods for measurement and analysis of landscape pattern. Nowosad and Stepinski (2019, this issue) derive new information-theoretical metrics that specifically describe landscape complexity. Using simulated landscapes with four land cover classes each, the authors conclude that two pattern metricsjoint entropy, which describes the overall complexity of the landscape, and mutual information, which describes the aggregation of classes-are sufficient to describe landscape patterns. Zhai et al. (2019, this issue) show that transiograms, which are graphs of transition probabilities over a range of spatial lags, offer independent metrics to measure the spatial variability of categorical variables, such as soil types and land cover classes. Kedron et al. (2019, this issue) develop three-dimensional analogues of classical twodimensional patch-mosaic metrics, and discuss the relevance of those metrics to urban studies using a case study of the built environment in New Orleans. Tarr (2019, this issue) demonstrates a conceptual model specifically for multispecies landscape pattern measurement that combines species-specific requirements to identify hotspots for conservation protection and inform conservation strategies for those locations. Brooks and Lee (2019, this issue) introduce the agglomerative curve (AG-curve) and show that it can be used to distinguish different forms of forest disturbance. In the AG-curve method, a hierarchical clustering algorithm is run on the spatial coordinates of a disturbance or other phenomenon of interest and a curve is drawn to describe the rate at which they agglomerate into successively smaller numbers of clusters.

\section{Novel approaches and applications of pattern metrics}

Additional studies in this special issue apply landscape pattern metrics in new ways. Noting that the temporal aspect of landscape pattern has been under-studied, Corry (2019, this issue) shows that annual pattern measurements are necessary to capture pattern changes attributable to conventional agricultural crop rotations. Wickham and Riitters (2019, this issue) study patterns of forest fragmentation using highresolution satellite data. While they expect to detect ever-smaller canopy gaps, thus increasing measured forest fragmentation, the high-resolution data also detects smaller forest patches, leading to decreased forest fragmentation in some circumstances. Tackling the thorny problem of estimating Boltzmann (thermodynamic) entropy, Gao and $\mathrm{Li}$ (2019, this issue) explore the integration of approaches based on the 
patch-mosaic model (Cushman 2016) and the gradient model (Gao et al. 2017). While they show that the approaches do have some parallel elements, a general method of computing Boltzmann entropy for landscape ecology that integrates the two approaches is still lacking. Peterman et al. (2019, this issue) compare approaches to constructing genetic resistance maps and conclude the best match to true resistance maps was obtained by adaptive optimization incorporating a genetic algorithm.

\section{Ways forward}

The contributions to this special issue demonstrate that landscape pattern analysis is an active research field that is producing tools and insights that are critical for landscape ecology and related disciplines. The history and current status of landscape pattern measurement will likely provide hints about its future. Several of the perspectives in this issue point to the future (Frazier 2019, this issue; Gustafson 2019, this issue; Vogt 2019, this issue), as have other recent reviews of pattern metrics (Kupfer 2012; Lausch et al. 2015; Frazier and Kedron 2017). Landscape ecologists have repeatedly borrowed approaches from other fields and continue to do so. It is worth exploring whether there are other methods that could be borrowed, especially given the need for analyzing patterns across nongeographic domains such as soundscapes (Pijanowski et al. 2011).

The future applications of landscape pattern metrics will almost certainly depend on the software and analysis tools available. The software FRAGSTATS (McGarigal and Marks 1995) is often cited as a catalyst for early developments in the field of landscape ecology (Gustafson 2019, this issue). Indeed, Gustafson (2019, this issue) stated that software not only facilitates the adoption of metrics and analysis approaches, but also drives or constrains subsequent conceptual advances. Another example is GuidosToolbox (Vogt and Riitters 2017), which has facilitated the use of MSPA metrics (Schulz and Schröder 2017; Simonson et al. 2018; Vogt 2019, this issue). Freely-available software, TGRAM, is now available to estimate transiograms from maps or imagery (Yu et al. 2019; Zhai et al. 2019, this issue). Conversely, surface metrics (McGarigal et al. 2009; Kedron et al. 2018) are notable new metrics but are not yet widely used, likely in part because they have not been integrated into any software package that is used by ecologists. We note, however, that an R package for calculating surface metrics has been developed recently (Smith et al. 2019, available at https:// github.com/bioXgeo/geodiv) and their integration into FRAGSTATS is imminent (http://www.umass. edu/landeco/research/fragstats/documents/fragstats. help.4.pdf). Usability, user-centered design, and specifically the ability of users to visualize pattern metrics and the results of pattern analysis are essential components of software design in landscape ecology (Vogt 2019, this issue).

The perspective in this issue by Frazier (Frazier 2019, this issue) also mentioned that borrowing tools and concepts from the medical sciences and economics to facilitate reproducibility and replication $(\mathrm{R}$ $\& \mathrm{R})$ would enable transdisciplinarity in landscape pattern analysis. While it may not be possible to fully reproduce many ecological studies, we think that the development and usage of a set of well-defined metrics to analyze landscape pattern can be a critical part of a culture of computational reproducibility across the field of landscape ecology. Computational reproducibility is the ability to produce equivalent outcomes from the same data set using the same software and code (Powers and Hampton 2019). Freely available software, along with pattern metrics that are useful in a wide range of studies certainly contribute to $\mathrm{R} \& \mathrm{R}$ in landscape ecology.

In conclusion, the contributions to this special issue reflect the two parallel developments of landscape pattern metrics that dominate the history of landscape ecology. One has been the search for generality and scaling, including determining the minimum set of metrics with which to measure pattern in any landscape for a wide range of purposes. The other has been developing tailored metrics that could have widespread use for a specific type of analysis. For the same reasons that both up-scaling and down-scaling are complimentary approaches to solving the problem of cross-scale analysis, we believe that both approaches to pattern metric development are valid and useful. By developing and examining the performance and limitations of both general and specific metrics, landscape ecologists have a key role to play in the integration of landscape pattern measurement across many fields in ecology and related disciplines. 


\section{References}

Baker WL, Cai Y (1992) The r.le programs for multiscale analysis of landscape structure using the GRASS geographical information system. Landsc Ecol 7:291-302

Beier P, Brost B (2010) Use of land facets to plan for climate change: conserving the arenas, not the actors. Conserv Biol 24:701-710

Bogaert J (2003) Lack of agreement on fragmentation metrics blurs correspondence between fragmentation experiments and predicted effects. Conserv Ecol 7:r6

Brooks B-GJ, Lee DC (2019) Feasibility of pattern type classification for landscape patterns using the AG-curve. Landsc Ecol. https://doi.org/10.1007/s10980-019-00869-w

Corry P (2019) How measures of agricultural landscape patterns are affected by crop rotation dynamics. Landsc Ecol. https://doi.org/10.1007/s10980-019-00823-w

Cushman SA (2016) Calculating the configurational entropy of a landscape mosaic. Landsc Ecol 31:481-489

Cushman SA, Huettmann F (2010) The gradient paradigm: a conceptual and analytical framework for landscape ecology

Elith J, Graham CH, Anderson RP, Dudık M, Ferrier S, Guisan A, Hijmans RJ, Huettmann F, Leathwick JR, Lehmann A, Li J, Lohmann LG, Loiselle BA, Manion G, Moritz C, Nakamura M, Nakazawa Y, Jacob McC M, Overton A, Peterson T, Phillips SJ, Richardson K, Scachetti-Pereira R, Schapire RE, Soberón J, Williams S, Wisz MS, Zimmermann NE (2006) Novel methods improve prediction of species' distributions from occurrence data. Ecography 29:129-151

Fei S, Guo Q, Potter K (2016) Macrosystems ecology: novel methods and new understanding of multi-scale patterns and processes. Landsc Ecol 31:1-6

Fischer J, Lindenmayer DB (2007) Landscape modification and habitat fragmentation: a synthesis. Glob Ecol Biogeogr 16:265-280

Forman RTT, Godron M (1981) Patches and structural components for a landscape ecology. Bioscience 31:733-740

Franklin J, Serra-Diaz JM, Syphard AD, Regan HM (2017) Big data for forecasting the impacts of global change on plant communities. Glob Ecol Biogeogr 26:6-17

Frazier AE (2019) Emerging trajectories and interdisciplinary perspectives for spatial pattern analysis. Landsc Ecol. https://doi.org/10.1007/s10980-019-00880-1

Frazier AE, Kedron P (2017) Landscape metrics: past progress and future directions. Curr Landsc Ecol Rep. https://doi. org/10.1007/s40823-017-0026-0

Gao P, Li Z (2019) Computation of the Boltzmann entropy of a landscape: a review and a generalization. Landsc Ecol. https://doi.org/10.1007/s10980-019-00814-x

Gao P, Zhang H, Li Z (2017) A hierarchy-based solution to calculate the configurational entropy of landscape gradients. Landsc Ecol 32:1133-1146

Gardner RH, Milne BT, Turner MG, O’Neill RV (1987) Neutral models for the analysis of borad scale landscape pattern. Landsc Ecol 1:19-28

Gustafson E (1998) Quantifying landscape spatial pattern: what is the state of the art. Ecosystems 1:143-156
Gustafson E (2019) How has the state-of-the-art for quantification of landscape pattern advanced in the twenty-first century? Landsc Ecol. https://doi.org/10.1007/s10980018-0709-x

Hampton SE, Strasser CA, Tewksbury JJ, Gram WK, Budden AE, Batcheller AL, Duke CS, Porter JH (2013) Big data and the future of ecology. Front Ecol Environ 11:156-162. https://doi.org/10.1890/120103

Hjort J, Gordon JE, Gray M, Hunter ML (2015) Why geodiversity matters in valuing nature's stage. Conserv Biol 29:630-639

Kedron PJ, Frazier AE, Ovando-Montejo GA, Wang J (2018) Surface metrics for landscape ecology: a comparison of landscape models across ecoregions and scales. Landsc Ecol. https://doi.org/10.1007/s10980-018-0685-1

Kedron P, Zhao Y, Frazier A (2019) Three dimensional (3D) spatial metrics for objects. Landsc Ecol. https://doi.org/10. 1007/s10980-019-00861-4

Keitt TH, Urban DL, Milne BT (1997) Detecting critical scales in fragmented landscapes. Conserv Ecol 1:4

Kong F, Yin H, James P, Hutyra LR, He HS (2014) Effects of spatial pattern of greenspace on urban cooling in a large metropolitan area of eastern China. Landsc Urban Plan 128:35-47. https://doi.org/10.1016/j.landurbplan.2014.04. 018

Krummel JR, Gardner RH, Sugihara G, O'Neill RV, Coleman PR (1987) Landscape patterns in a disturbed environment. Oikos 48:321-324

Kupfer JA (2012) Landscape ecology and biogeography: rethinking landscape metrics in a post-FRAGSTATS landscape. Prog Phys Geogr 36:400-420

Lausch A, Blaschke T, Haase D, Herzog F, Syrbe RU, Tischendorf L, Walz U (2015) Understanding and quantifying landscape structure - A review on relevant process characteristics, data models and landscape metrics. Ecol Model 295:31-41. https://doi.org/10.1016/j.ecolmodel.2014.08. 018

Lawler JJ, Ackerly DD, Albano CM, Anderson MG, Dobrowski SZ, Gill JL, Heller NE, Pressey RL, Sanderson EW, Weiss SB (2015) The theory behind, and the challenges of, conserving nature's stage in a time of rapid change. Conserv Biol 29:618-629. https://doi.org/10.1111/cobi.12505

Levins R (1966) The strategy of model building in population biology. Am Sci 54:421-431

Li H, Wu J (2004) Use and misuse of landscape indices. Landsc Ecol 19:389-399

Li X, Zhou W, Ouyang Z (2013) Relationship between land surface temperature and spatial pattern of greenspace: what are the effects of spatial resolution? Landsc Urban Plan 114:1-8

McGarigal K, Marks B (1995) FRAGSTATS: spatial pattern analysis program for quantifying landscape structure. United States Dep Agric Pacific Northwest Res Station. https://doi.org/10.1061/(ASCE)0733-9437(2005)131: 1(94)CE

McGarigal K, Tagil S, Cushman SA (2009) Surface metrics: an alternative to patch metrics for the quantification of landscape structure. Landsc Ecol 24:433-450

McIntyre S, Barrett GW (1992) Habitat variegation, an alternative to fragmentation. Conserv Biol 6:146-147 
McIntyre S, Hobbs R (1999) A framework for conceptualizing human effects on research models. Conserv Biol 13:1282-1292

McRae BH (2008) Using circuit theory to model connectivity in ecology, evolution, and conservation. Ecology $89: 2712-2724$

Milne BT (1988) Measuring the fractal geometry of landscapes. Appl Math Comput 27:67-79

Milne BT (1992) Spatial aggregation and neutral models in fractal landscapes. Am Nat 139:32-57

Morrison SA, Sillett TS, Funk WC, Ghalambor CK, Rick TC (2017) Equipping the 22nd-century historical ecologist. Trends Ecol Evol 32:578-588. https://doi.org/10.1016/j. tree.2017.05.006

Nowosad J, Stepinski TF (2019) Information theory as a consistent framework for quantification and classification of landscape patterns. Landsc Ecol. https://doi.org/10.1007/ s10980-019-00830-x

O’Neill RV, Krummel JR, Gardner RH, Sugihara G, Jackson B, DeAngelis DL, Milne BT, Turner MG, Zygmunt B, Christensen SW, Dale VH, Graham RL (1988) Indices of landscape pattern. Landsc Ecol 1:153-162. https://doi.org/ 10.1007/BF00162741

Peterman WE, Winiarski KJ, Moore CE, Carvalho S, Gilbert AL, Spear SF (2019) A comparison of popular approaches to optimize landscape resistance surfaces. Landsc Ecol. https://doi.org/10.1007/s10980-019-00870-3

Pettorelli N, Safi K, Turner W (2014) Satellite remote sensing, biodiversity research and conservation of the future. Philos Trans R Soc Lond B 369:20130190

Pielou EC (1975) Ecological diversity. Wiley, New York

Pijanowski BC, Farina A, Gage SH, Dumyahn SL, Krause BL (2011) What is soundscape ecology? An introduction and overview of anemerging new science. Landsc Ecol 26:1213-1232. https://doi.org/10.1007/s10980-011-96008

Plotnick RE, Gardner RH, O’Neill RV (1993) Lacunarity indices as measures of landscape texture. Landsc Ecol 8:201-211

Potter KM, Koch FH, Oswalt CM, Iannone BV (2016) Data, data everywhere: detecting spatial patterns in fine-scale ecological information collected across a continent. Landsc Ecol 31:67-84

Powers SM, Hampton SE (2019) Open science, reproducibility, and transparency in ecology. Ecol Appl 29:1-8

Riitters K (2019) Pattern metrics for a transdisciplinary landscape ecology. Landsc Ecol. https://doi.org/10.1007/ s10980-018-0755-4

Saura S, Torné J (2009) Conefor Sensinode 2.2: a software package for quantifying the importance of habitat patches for landscape connectivity. Environ Model Softw 24:135-139

Schneider A, Woodcock CE (2008) Compact, dispersed, fragmented, extensive? A comparison of urban growth in 25 global cities using remotely sensed data, pattern metrics and census information. Urban Stud 45:659-692

Schulz JJ, Schröder B (2017) Identifying suitable multifunctional restoration areas for forest landscape restoration in Central Chile. Ecosphere. https://doi.org/10.1002/ecs2. 1644
Simonson WD, Allen HD, Parham E, Eduardo de Basto e Santos, Paul H (2018) Modelling biodiversity trends in the montado (wood pasture)landscapes of the Alentejo, Portugal. Landsc Ecol 33:811-827. https://doi.org/10.1007/ s10980-018-0627-y

Smith AC, Dahlin KM, Zarnetske PL (2019) geodiv: Methods for Calculating Gradient Surface Metrics. R package version 0.1 .0

Soille P, Vogt P (2009) Morphological segmentation of binary patterns. Pattern Recognit Lett 30:456-459

Tarr NM (2019) Demonstrating a conceptual model for multispecies landscape pattern indices in landscape conservation. Landsc Ecol. https://doi.org/10.1007/s10980-01900888-7

Turner MG, Gardner RH (1991) Quantitative methods in landscape ecology: the analysis and interpretation of landscape heterogeneity. Springer-Verlag, New York

Urban D, Keitt T (2001) Landscape connectivity: a graph-theoretic perspective. Ecology 82:1205-1218

Urban DL, O'Neill RV, Shugart HH (1987) Landscape ecology: a hierarchical perspective can help scientists understand spatial patterns. Bioscience 37:119-127

Uuemaa E, Mander Ü, Marja R (2013) Trends in the use of landscape spatial metrics as landscape indicators: a review. Ecol Indic 28:100-106

Vogt P (2019) Patterns in software design. Landsc Ecol. https:// doi.org/10.1007/s10980-019-00797-9

Vogt P, Riitters K (2017) GuidosToolbox: universal digital image object analysis. Eur J Remote Sens 50:352-361

Vogt P, Riitters KH, Estreguil C et al (2007) Mapping spatial patterns with morphological image processing. Landsc Ecol 22:171-177

Vogt P, Ferrari JR, Lookingbill TR, Gardner RH, Riitters KH, Ostapowicz K (2009) Mapping functional connectivity. Ecol Indic 9:64-71. https://doi.org/10.1016/j.ecolind. 2008.01.011

Wickham JD, Riitters KH (2019) Influence of high-resolution data on the assessment of forest fragmentation. Landsc Ecol. https://doi.org/10.1007/s10980-019-00820-Z

Wu J (2013) Landscape sustainability science: ecosystem services and human well-being in changing landscapes. Landsc Ecol 28:999-1023

Yu J, Li W, Zhang C (2019) A framework of experimental transiogram modelling for Markov chain geostatistical simulation of landscape categories. Comput Environ Urban Syst 73:16-26

Zarnetske PL, Read QD, Record S, Gaddis K, Pau S, Hobi M, Malone S, Costanza J, Dahlin KM, Latimer AM, Wilson AM, Grady J, Ollinger SV, Finley AO (2019) Towards connecting biodiversity and geodiversity across scales with satellite remote sensing. Glob Ecol Biogeogr 28(5):548-556. https://doi.org/10.1111/geb.12887

Zhai R, Li W, Zhang C, Zhang W, Wang W (2019) The transiogram as a graphic metric for characterizing the spatial patterns of landscapes. Landsc Ecol. https://doi.org/10. 1007/s10980-018-0760-7

Publisher's Note Springer Nature remains neutral with regard to jurisdictional claims in published maps and institutional affiliations. 